Original Article

\title{
A Study on Knowledge and Practice on Maternal Bed sharing Among Mothers in A Selected Hospital at Mangalore
}

\author{
Rikynti Nongkynrih', Savitha Pramilda Cutinho², Victoria D'almeida ${ }^{3}$ \\ ${ }^{1}$ M Sc Nursing, ${ }^{2}$ Professor and HOD, Department Of Obstetrics and Gynaecological Nursing, ${ }^{3}$ Professor, Department of \\ M edical Surgical Nursing, Father M uller College Of Nursing, Kankanady, Mangalore - 575002. \\ *Corresponding Author : Rikynti Nongkynrih, M.Sc., Nursing, Department of Obstetrics and Gynaecological Nursing, Father Muller \\ College Of Nursing, Kankanady, M angalore-575002, Mobile: +9191087 71043 E-mail : rikyntinongkynrih@gmail.com
}

Received

: 12.06 .2017

Review Completed : 15.07.2017

Accepted

: 16.07 .2017

Keywords : M aternal bed sharing, SIDS (Sudden Infant Death Syndrome), Knowledge, Practice.

\begin{tabular}{|c|}
\hline Access this article online \\
\hline Quick Response Code \\
\hline
\end{tabular}

\begin{abstract}
:
A non-experimental descriptive correlative research design was used to assess the knowledge and practice of 100 mothers whose babies are within 0-3 1/2 months of age regarding maternal bed sharing. The sample was recruited by purposive sampling technique. A structured knowledge questionnaire and a self report practice checklist were used to collect the data. The finding in the current study reveals that $50 \%$ of the mothers had an average knowledge and $46 \%$ had poor knowledge whereas $4 \%$ had very good knowledge on maternal bed sharing and the mean on safe practice (14.42) is more than that of unsafe practice (12.52) which shows that the mothers were following safe practices. There was no significant association of knowledge and practice of mothers with selected demographic variables; however there is an association on practice of maternal bed sharing with educational status and number of children. The results showed that although the mothers had an average knowledge regarding maternal bed sharing but their practices were safe. M others with good knowledge can bring down the Sudden Infant death rate.
\end{abstract}

\section{Introduction}

Bed sharing, co-bedding and co-sleeping are terms that have been used to describe the practice of caregivers sharing bed with infants which is a relatively common practice around the world. Bed sharing has benefits but the risks of serious injury to infants are concerning the health care professionals who care for infants and their families. ${ }^{1}$

Rooming -in is now recommended by the World Health Organization (WHO) and UNICEF as part of the Baby Friendly Hospital Initiative (BFHI) programme to promote breastfeeding. ${ }^{2}$ Leguien and Carpentier reported an increase risk for Sudden Infant death syndrome when bed sharing is associated with maternal alcohol consumption and smoking and Carroll-Pankhrust and Mortimer concluded that bed sharing was related to some SIDS like deaths, particularly if the adult was of large size. ${ }^{1}$

The association between bed sharing and sudden infant death has been recognised for thousands of years. Indeed there is reference to it in the Holy Bible: "thiswoman's child died in the night; because she overlaid it" Overlaying was the classical belief for the cause of sudden infant death. ${ }^{3}$

A detailed case-control study which was conducted for all sudden unexpected deaths in infancy in the participating regions of the United Kingdom showed that Bed sharing for the whole night was a significant risk factor for infants whose mothers smoked. This study confirms the importance of certain risk factors for the sudden infant death syndrome and identifies others-for example covers over the head, side sleeping position-which may be amenable to change by educating and informing parents and health care professionals. ${ }^{4}$

A descriptive study was conducted in Canada to determine mother practices and experiences of bed sharing with their infants and also to determine knowledge of the risks. They 
used a self report questionnaire where it was mailed to 1,122 mothers of infants whose infants aged three months. The results showed that 293 completed questionnaires received (26\% return rates). Approximately $13 \%$ of respondents who had bed shared reported an experience with bed sharing in which they had rolled onto or partway onto their infant. The study concluded that health care professionals should promote mothers in providing safe sleeping environment to their infants. ${ }^{1}$

M any studies have dealt with topics like bed-sharing safety but very few of them have studied mothers' practices, preferences and knowledge about parent co-sleeping. A better understanding of the motivations and knowledge in the community could help medical personnel to deal with the topic. As midwives, the main role is to properly assess the knowledge and practice of mothers regarding maternal bed sharing compared to no bed sharing. During the clinical experience, the investigator came across mothers who were practicing bed sharing with their babies which were unsafe practices like covering the baby's head, putting extra pillows and clothes near to the baby, being too close to the mother that it covers the nose of the baby which can lead to suffocation and deaths of the baby's and though they have knowledge of what they practice, but it was not enough. This prompted the investigator to undertake a study on knowledge and practice on maternal bed sharing among mothers whose babies are within the age group 0-3 $1 / 2$ months of age.

\section{Objectives of the Study}

1. To determine the knowledge regarding maternal bed sharing among mothers using structured knowledge questionnaire.

2. To determine the maternal bed sharing practices among mothers using practice checklist.

3. To find the correlation between knowledge and practice on maternal bed sharing among mothers.

4. To find the association of knowledge on maternal bed sharing with selected demographic variables.

5. To find the association of maternal bed sharing practice with selected demographic variables.

\section{Research Methodology}

A Quantitative research approach with non-experimental descriptive correlative research design was used to assess the knowledge and practice of 100 mothers whose babies are within $0-3 \frac{1}{2}$ months of age regarding maternal bed sharing. The ethical clearance has been obtained from the ethical committee before proceeding for the main study. The sample was recruited by purposive sampling technique. The investigator explained the purpose of the study to the mothers to win their cooperation. Confidentiality was assured and informed consent was taken from every mother. The tool was administered to the participants with proper explanation. A structured knowledge questionnaire and a self report practice checklist were used to collect the data. The data was tabulated and analysed using descriptive and inferential statistics.

\section{Results}

\section{Baseline data}

Out of 100 mothers whose babies are within 0-31/2 months of age, 46 ( $46 \%$ ) percent of the subjects are in the age group 21-24 years. Majority of the subjects were from an Islam religion 70 (70\%). 54 (54\%) of the respondents are staying in a joint family, most of the subjects had Primary school and high school education 31(31\%). Majority of their family income 37 (37\%) is between Rs. 5,001-10,000. M ajority of the subjects had only 1 child 50 (50\%), 67 (67\%) of them have a child who is below 3 months of age, 100 (100\%) of their babies slept beside the mother on the same bed, 89 ( $89 \%$ ) of their babies always sleeps beside the mother on the same bed.

\section{Knowledge of the mothers on M aternal Bed sharing}

Data in table 1 and figure 1 reveals that 50 mothers (50\%) had an average knowledge and 46 mothers (46\%) had poor knowledge on maternal bed sharing whereas few had very good knowledge (4\%) on maternal bed sharing.

\section{Practice of Maternal Bed sharing among M others}

Data in table 2 reveals that all the $99 \%$ of the mother place her baby adjacent to herself while sleeping, $93 \%$ of the mother tie her hair before sleeping with her baby, $90 \%$ 
baby face is kept clear while sleeping, $84 \%$ mothers slept with their baby in a comfortable big size bed, $84 \%$ slept in a well ventilated room, $71 \%$ of the mothers kept their baby on his/her back while sleeping, $66 \%$ baby is not placed in between mother and father while sleeping and 55\% M other don't sleep with baby if she's too tired.

The unsafe practices that are common to maximum number of mothers are listed in Table 3 along with the frequency and percentage, the table reveals that $95 \%$ of the baby sleeps in a very soft mattress, $72 \%$ of the mothers are putting slats side rails while sleeping with the baby, $66 \%$ kept soft dolls and pillows near to the baby while sleeping, $47 \%$ of the babies sleeps with his or her siblings, $30 \%$ of the mothers cover the baby with more than one blanket while sleeping, $19 \%$ of the mothers breastfeed their baby on the sofa and $13 \%$ of the mothers are placing the baby near to the curtains while sleeping and $8 \%$ of the family members are smoking.

\section{Comparison of Safe and Unsafe practices on Maternal Bed sharing amongmothers}

Data presented in table 4 shows that the mean of safe practice is more than that of unsafe practice and the $p$ value $(p=0.001)$ is less than the 0.05 which suggest that there was a significant differences in the practice of safe and unsafe practices among mothers on maternal bed sharing. Therefore most of the mother's maternal bed sharing practice was safe.

\section{Correlation between Knowledge and Practice on Maternal Bed sharingamong M others}

Data from Table 5 reveals that $r$ value is 0.3 and the $p$ value is 0.01 which is significant at 0.05 level of significance. There is a moderate positive correlation between knowledge and practice on maternal bed sharing. Thus the research hypothesis $\left(\mathrm{H}_{1}\right)$ was accepted and null hypothesis $\left(\mathrm{H}_{01}\right)$ was rejected and figure 2 shows that as knowledge increases there was moderate increase in the practice on maternal bed sharing.

\section{Association of Knowledge on Maternal Bed sharing with Selected Demographic Variables}

There was no association between knowledge and practice on maternal bed sharing with the selected demographic variables (Age of the mothers, type of family, educational status, monthly income and age of the last child). But there was an association between the practice on maternal bed sharing with selected demographic variables like educational status and the number of children with the calculated $p$ value wasless than $0.05(p \varangle 0.005)$.

Table 1 : Grading on Knowledge of the mothers

\begin{tabular}{|c|c|c|}
\hline Knowledge Score & Range in percentage & Grading \\
\hline 17 and above & 94 and above & Excellent \\
\hline $13-17$ & $72-94$ & Very good \\
\hline 9-13 & $50-72$ & Average \\
\hline Below 9 & Below 50 & Poor \\
\hline
\end{tabular}

Max. Score=18

Table 2: Frequency and Percentage Distribution of Reported Safe Practices of mothers on M aternal Bed sharing

$n=100$

\begin{tabular}{|c|c|c|c|}
\hline $\begin{array}{l}\text { SI } \\
\text { No. }\end{array}$ & Reported Safe Practices & $\begin{array}{l}\text { Frequency } \\
\text { (f) }\end{array}$ & $\begin{array}{c}\text { Percentage } \\
(\%)\end{array}$ \\
\hline 1 & $\begin{array}{l}\text { M other places her baby adjacent } \\
\text { to herself while sleeping }\end{array}$ & 99 & 99 \\
\hline 2 & $\begin{array}{l}\text { M other ties her hair before } \\
\text { sleeping with her baby }\end{array}$ & 93 & 93 \\
\hline 3 & $\begin{array}{l}\text { Baby's face is kept clear } \\
\text { while sleeping }\end{array}$ & 90 & 90 \\
\hline 4 & $\begin{array}{l}\text { M other sleeps with her baby in } \\
\text { a comfortable big size bed }\end{array}$ & 84 & 84 \\
\hline 5 & Sleeps in a well ventilated room & 84 & 84 \\
\hline 6 & $\begin{array}{l}\text { Keeps baby on his/her back } \\
\text { while sleeping }\end{array}$ & 71 & 71 \\
\hline 7 & $\begin{array}{l}\text { Baby is not placed in between } \\
\text { mother and father while sleeping }\end{array}$ & 66 & 66 \\
\hline 8 & M other does not sleep with baby & 55 & 55 \\
\hline
\end{tabular}

Table 3 : Frequency and Percentage Distribution of reported Unsafe Practices of mothers on M aternal Bed sharing $\quad \mathbf{n = 1 0 0}$

\begin{tabular}{|c|c|c|c|}
\hline $\begin{array}{l}\text { SI } \\
\text { no }\end{array}$ & Reported Unsafe Practice & $\begin{array}{l}\text { Frequency } \\
\text { (f) }\end{array}$ & $\begin{array}{c}\text { Percentage } \\
(\%)\end{array}$ \\
\hline 1 & $\begin{array}{l}\text { M y baby sleeps in very soft } \\
\text { mattress }\end{array}$ & 95 & 95 \\
\hline 2 & $\begin{array}{l}\text { Puts slats side rails while sleeping } \\
\text { with the baby }\end{array}$ & 72 & 72 \\
\hline 3 & $\begin{array}{l}\text { Soft dolls and pillows are kept } \\
\text { near to the baby while sleeping }\end{array}$ & 66 & 66 \\
\hline 4 & $\begin{array}{l}\text { My little one sleeps with } \\
\text { his/her siblings }\end{array}$ & 47 & 47 \\
\hline 5 & $\begin{array}{l}\text { Covers the baby with more than } \\
\text { one blanket while sleeping }\end{array}$ & 30 & 30 \\
\hline 6 & Breastfeeds the baby on the sofa & 19 & 19 \\
\hline
\end{tabular}




\begin{tabular}{clcc}
\hline $\begin{array}{c}\text { SI } \\
\text { no }\end{array}$ & Reported Unsafe Practice & $\begin{array}{c}\text { Frequency } \\
\text { (f) }\end{array}$ & $\begin{array}{c}\text { Percentage } \\
\text { (\%) }\end{array}$ \\
\hline 7 & Places the baby near to the & 13 & 13 \\
$\begin{array}{l}\text { curtains while sleeping } \\
8\end{array}$ & $\begin{array}{l}\text { There are family members } \\
\text { who smoke }\end{array}$ & 8 & 8 \\
\hline
\end{tabular}

Table 4 : Comparison of Safe and Unsafe practices on Maternal Bed sharing among mothers $n=100$

\begin{tabular}{lcccc}
\hline Practice & Mean \pm SD & $\begin{array}{c}\text { Mean } \\
\text { Difference }\end{array}$ & $\begin{array}{c}\text { Obtained } \\
\text { ' } t \text { ' value }\end{array}$ & $\begin{array}{c}\text { 'p' } \\
\text { value }\end{array}$ \\
\hline $\begin{array}{l}\text { Safe practice } \\
\text { Unsafe practice }\end{array}$ & $14.42 \pm 1.18$ & 1.9 & 9.7 & $0.001^{* *}$ \\
\hline$t_{99}=1.98, p \leq 0.05$ & \multirow{4}{*}{$* 0.05$ level of significance }
\end{tabular}

Table 5 : Correlation between Knowledge and Practice on M aternal Bed sharing among $M$ others

\begin{tabular}{lllll}
\hline Variables & Mean & SD & rvalue & pvalue \\
\hline Knowledge & 8.57 & 2.33 & \multirow{2}{*}{317} & $.001^{*}$ \\
Practice & 26.94 & 1.46 & & \\
\hline
\end{tabular}

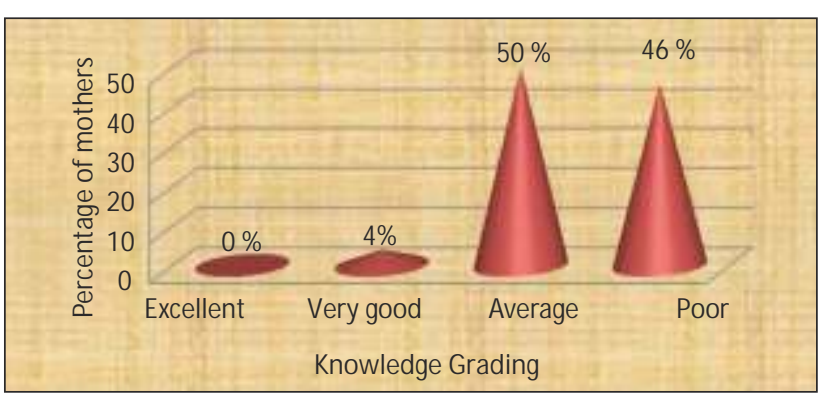

Figure 1 : Bar Diagram Showing the Percentage Distribution of mothersaccording to their Grade

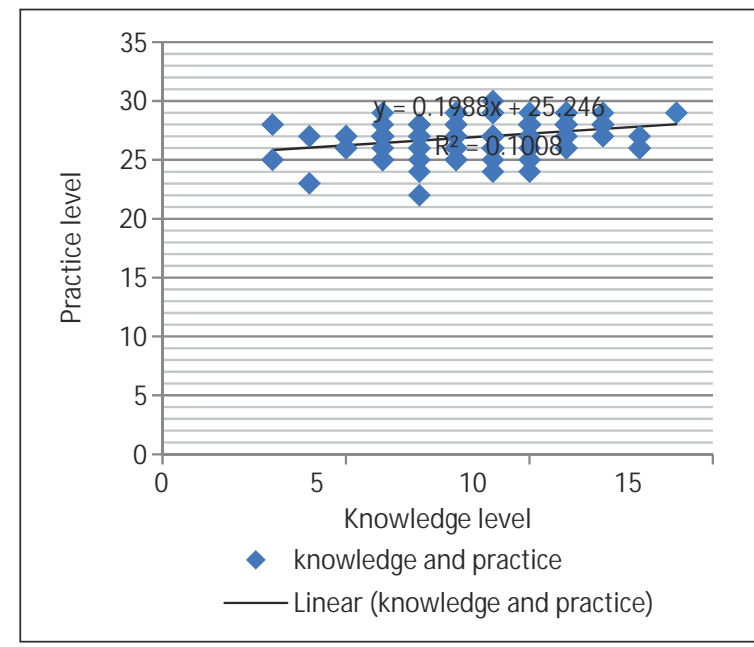

Figure 2 : Correlation between Knowledge and Practice

\section{Discussion}

The findings in the study about educational status of the mothers revealed that $31 \%$ had completed their primary and High school education, whereas 20\% completed their pre university, $13 \%$ are graduates and only $4 \%$ completed their post graduate, $1 \%$ no basic education. The findings in the study support the findings that was found out in the study conducted by Tan K L, Ghani S N, M oy F M on The Prevalence and Characteristics Associated with MotherInfant Bed-Sharing in Klang District, M alaysia reveals that out of 682 mothers who share bed with their infants $78.1 \%$ mothers had secondary school education, $5.9 \%$ completed their primary school and $16 \%$ completed their diploma course. ${ }^{5}$ The findings in the study contradict with the study findings with that of the study conducted by Ateah AC, Hameline KJ on Maternal Bed Sharing Practices, Experiences, and Awareness of Risks shows that out of 212 mothers who share bed with their infants reveals that $36.3 \%$ completed their college diploma, 30.2\% had their university degree, $24.1 \%$ had their high school diploma and $9.4 \%$ had completed only till the 12 grade. ${ }^{1}$

The findings in the study reveal that $50 \%$ of the subjects had an average knowledge on maternal bed sharing and only $46 \%$ had poor knowledge on maternal bed sharing. The findings is supported with the study findings with that of the study conducted by Ateah AC, Hameline $\mathrm{KJ}$ on Maternal Bed Sharing Practices, Experiences, and Awareness of Risks shows that $88.7 \%$ of the mothers had knowledge about maternal bed sharing and its risk whereas $10 \%$ agreed that there were no risk on bed sharing with their infant. ${ }^{1}$

The reported safety practices of maternal bed sharing in the current study reveals the findings $99 \%$ of the mother place her baby adjacent to herself while sleeping, $93 \%$ of the mother tie her hair before sleeping with her baby, $90 \%$ baby face is kept clear while sleeping, $84 \%$ mother sleeps with her baby in a comfortable big size bed, $84 \%$ Sleeps in a well ventilated room, $71 \%$ baby is kept on his/her back while sleeping, $66 \%$ baby is not placed in between mother and father while sleeping and 55\% M other don't sleep with baby if she's too tired. The findings in the study support the study findings with that of the study conducted by Hutchison BL, Thompson JM, M itchell EA on Infant care 
practices related to sudden unexpected death in infancy: a

2013 survey shows that $74 \%$ of the mothers are placing their infant in the supine position which is the safe practice which they are practicing, whereas $53 \%$ of the mothers are placing their infant either in the side, back and prone position. ${ }^{6}$

\section{Recommendations}

1. A similar study can be replicated using a larger sample to generalize the findings.

2. A similar study can be conducted by utilising teaching strategies and demonstrations.

3. A comparative study can be conducted between health professionalsand non health professionals.

4. A similar study can be conducted to assess the knowledge of the staff nurses who are on night duties on maternal bed sharing.

\section{Reference}

1. Ateah AC, Hameline KJ. Maternal Bed Sharing Practices, Experiences, and Awareness of Risks. J Gynae Neon Nursg [Internet]. 2008 M ay-Jun [cited 2016 Feb 1st]; 37(3):274-281. Available from: URL:http://jognn.awhonn.org.

2. Das RR, Sankar MJ, Agarwal R and Paul VK. Is "Bed sharing Beneficial and Safe during Infancy? A systematic Review. Int J Pead [Internet].2014 Jan [cited 2016 Jan 13th]; 6(3): 1-16.Available from: URL: http://www.hindawi.com/journals/ijpedi/2014/468538/.

3. Mitchell EA. Bedsharing and the risk of Sudden Infant Death: Parents Need Clear Information. Current Paediatric Reviews [Internet].2010 Feb [cited 2017 March 11th]; 63(1):63-66.Available from URL: http://www.ingentaconnect.com/content/ben/cpr/2010/00000006/ 00000001/art00012.

4. Fleming PJ, Bensley D, Blair PS, Bacon C, Smith I, et al. Environment of infants during sleep and risk of the sudden infant death syndrome: results of 1993-1995 case-control study for confidential inquiry into stillbirths and deaths in infancy. Brit M ed ] [Internet]. 1996 Jul [cited 2016 March 11th]; 313(7051): 191-5. Available from: URL: http://www.bmj.com/content/313/7051/191.

5. Tan KL, Ghani SN, Moy FM. To determine the prevalence and characteristics of mother- infant bedsharing practice in Klang district. Medical Journal of M alaysia [Internet]. 2009 Dec [cited 2017 March 11th]; 64(4):311-315. Available from: URL: https://www. researchgate.net/profile/Foong- Ming_M oy/ publication / 47457722 The_prevalence_and_characteristics_associated_with_mother infant_bed-sharing_in_Klang_district_M Malaysia/links/0fcfd50 0 .

6. Hutchison BL, Thompson JM, M itchell EA. Infant care practices related to sudden unexpected death in infancy: a 2013 survey. N Zed Med J [Internet].2015 Jan [cited 2016 Nov 6th]; 128(1408):15-22. Available from: URL: https://www.ncbi.nlm.nih.gov/pubmed/25662375.

\section{Conclusion}

It is concluded that although the mothers had an average knowledge regarding maternal bed sharing but their practices were safe. Mothers with good knowledge can bring down the Sudden Infant death rate. Better the knowledge best is the practice.

\section{Acknowledgement}

With profound sentiments and heartfelt gratitude, I offer my sincere thanks to all who have contributed to the growth of this dissertation.

I praise and thank the Almighty, the source of all knowledge and wisdom for his strength and inspiration throughout this research endeavour.

My sincere gratitude to the administrator of the institute, my guide, co-guide, the participants who have contributed to the growth of this dissertation. 